\title{
Hydrogen peroxide and nitric oxide in exhaled air of children with cystic fibrosis during antibiotic treatment
}

\author{
Q. Jöbsis*,\#, H.C. Raatgeep*, S.L. Schellekens*, A. Kroesbergen*, W.C.J. Hop ${ }^{+}$, J.C. de Jongste*
}

Hydrogen peroxide and nitric oxide in exhaled air of children with cystic fibrosis during antibiotic treatment. Q. Jöbsis, H.C. Raatgeep, S.L. Schellekens, A. Kroesbergen, W.C.J. Hop, J.C. de Jongste. C ERS Journals Ltd 2000.

ABSTRACT: Cystic fibrosis (CF) patients characteristically have severe chronic airway inflammation associated with bacterial infection. A noninvasive marker of airway inflammation could be a useful guide to treatment of $\mathrm{CF}$ lung disease. The aim of this study was to assess whether measurement of hydrogen peroxide $\left(\mathrm{H}_{2} \mathrm{O}_{2}\right)$ and nitric oxide (NO) in exhaled air can serve to monitor the effect of treatment with antibiotics in CF-children with acute infective pulmonary exacerbations.

Sixteen CF-patients (mean age 12.3 yrs) with exacerbation of their lung infection were treated with intravenous antibiotics in an uncontrolled study. During treatment, $\mathrm{H}_{2} \mathrm{O}_{2}$ in exhaled air condensate was measured twice a week. In addition, serial NO measurements were performed in nine patients.

During antibiotic treatment the median $\mathrm{H}_{2} \mathrm{O}_{2}$ concentration in exhaled air condensate decreased significantly from $0.28 \mu \mathrm{M}$ (range $0.07-1.20 \mu \mathrm{M})$ to $0.16 \mu \mathrm{M}$ (range $0.05-0.24 \mu M, p=0.002)$ and the mean forced expiratory volume in one second significantly increased from $55 \%$ predicted to $75 \%$ pred $(p=0.001)$. In individual subjects, changes of $\mathrm{H}_{2} \mathrm{O}_{2}$ and $\mathrm{FEV} 1$ between pairs of serial measurements correlated weakly $(p=0.08)$. Data on exhaled NO were inconclusive; exhaled NO did not change systematically during treatment.

It is concluded that cystic fibrosis patients with an acute pulmonary exacerbation have abnormally high concentrations of hydrogen peroxide, but not of nitric oxide, in exhaled air, which decrease during intravenous antibiotic treatment. Further controlled studies should establish if exhaled hydrogen peroxide, may serve as a noninvasive parameter of airway inflammation to guide antibiotic treatment in cystic fibrosis lung disease.

Eur Respir J 2000; 16: 95-100.

Invasive procedures such as bronchoscopy, bronchoalveolar lavage (BAL) and bronchial biopsies have greatly enhanced the understanding of the role of airway inflammation in various respiratory disorders like asthma and cystic fibrosis (CF). Lung disease in patients with CF is characterized by recurrent exacerbations of respiratory symptoms due to chronic bacterial infection of the airways. Shortly after birth, patients with CF acquire respiratory infection that incites an inflammatory response $[1,2]$. The continuous presence of bacteria in the lung induces a strong immunological response resulting in the release of inflammatory cytokines and mediators $[3,4]$ which can be measured in BAL fluid or sputum, even in young and stable CF-patients with clinically mild lung disease $[1,5$, 6]. In CF lung disease the inflammatory response leads to massive neutrophil recruitment $[5,6]$. Activated neutrophils and macrophages are major sources of oxygen free radicals including hydrogen peroxide $\left(\mathrm{H}_{2} \mathrm{O}_{2}\right)$. Indeed, lung infection in $\mathrm{CF}$ leads to increased oxygen free radical generation [7, 8]. Furthermore, sputum of CF-patients has been shown to prime neutrophils towards enhanced release of oxygen radicals [9]. The airways in patients

\begin{abstract}
*Dept. of Paediatrics/Respiratory Medicine and ${ }^{+}$Dept of Biostatistics, Erasmus University and University Hospital/Sophia Children's Hospital, Rotterdam, the Netherlands. "\#ept of Paediatrics, University Hospital, Maastricht, The Netherlands.
\end{abstract}

Correspondence: Q. Jöbsis

Dept of Paediatrics/Respiratory Medicine University Hospital

P.O. Box 5800

6202 AZ Maastricht

The Netherlands

Fax: 31433875246

Keywords: Antibiotics

children

cystic fibrosis

exhaled air

hydrogen peroxide

nitric oxide

Received: June 131999

Accepted after revision March 82000

This work was supported by research grant 94.14 of the Netherlands Asthma Foundation. with $\mathrm{CF}$ are exposed to increased oxidative stress which appears to be a result of lower airway inflammation [10].

The currently available methods to obtain material from the lower respiratory tract are in general inappropriate for routine use in the assessment of lower airway inflammation in children because of the invasive nature of these procedures. A simple, noninvasive test to monitor airway inflammation would be important for the diagnosis of airway inflammation and to evaluate current and new therapeutic options. Exhaled air (condensate) has been proposed as a noninvasive means of obtaining samples from the lower respiratory tract [11]. $\mathrm{H}_{2} \mathrm{O}_{2}$, a reactive oxygen radical, is a putative marker of airway inflammation in exhaled air condensate. An increased content of $\mathrm{H}_{2} \mathrm{O}_{2}$ has been described in exhaled air of patients with various inflammatory lung disorders [12-15]. Exhaled nitric oxide (NO) has been put forward as another noninvasive marker of airway inflammation $[16,17]$. However, in stable CF-patients orally exhaled NO levels are not elevated $[18,19]$. Data in children on $\mathrm{NO}$ and $\mathrm{H}_{2} \mathrm{O}_{2}$ during acute infectious respiratory tract exacerbation in $\mathrm{CF}$ are lacking. The aim of this study was to assess whether exhaled $\mathrm{H}_{2} \mathrm{O}_{2}$ and $\mathrm{NO}$ 
can serve as noninvasive markers of airway inflammation during treatment of $\mathrm{CF}$ patients with an acute infective pulmonary exacerbation.

\section{Methods}

\section{Study population}

Children with $\mathrm{CF}$ were recruited from the $\mathrm{CF}$-centre of the Sophia Children's Hospital (Rotterdam, the Netherlands). CF had been diagnosed on the basis of typical symptoms, two mutations in the CF-gene, and an abnormal sweat test (a sweat sodium concentration $>70 \mathrm{mmol} \cdot \mathrm{L}^{-1}$ ). Sixteen CF-patients with an acute infective pulmonary exacerbation, successively admitted for a course of inpatient $i . v$. antibiotic treatment, were included. Patients characteristics are shown in table 1. Exclusion criteria were: inability to perform pulmonary function tests; concomitant diagnosis of asthma; current oral steroid therapy; and a sputum culture containing Burkholderia cepacia. Disease severity of the subjects varied widely when they entered the study, with predicted forced expiratory volume in one second (FEV1) ranging 42-75\% (mean 55\%). Nine subjects used nebulized recombinant human dornase alpha. All subjects were infected with either Pseudomonas aeruginosa $(\mathrm{n}=10)$ or Staphyloccoccus aureus $(n=2)$ or a combination of the two organisms $(n=4)$. The study had an open, uncontrolled design. All patients received a standard treatment protocol, including $i . v$. antibiotics, based on bacterial sensitivities, and chest physiotherapy. The duration of the i.v. antibiotic therapy ranged 2-5 weeks (median 3 weeks). Informed consent for the study was obtained from the patients and parents on the day of admission. The study was approved by the medical ethical committee of the Erasmus University Medical Centre (Rotterdam, the Netherlands).

\section{Collection of exhaled air condensate}

The subjects breathed through a mouthpiece and a two way nonrebreathing valve (Rudolph Inc., Kansas City, MO, USA) which also served as a saliva trap. They were asked to breath at a normal frequency and tidal volume, wearing a nose clip. Exhaled air condensate was obtained by passing expired air through a $50 \mathrm{~cm}$ double jacketed glass tube cooled to a temperature of $0^{\circ} \mathrm{C}$, by means of

Table 1. - Patient characteristics before start of intravenous antibiotics

\begin{tabular}{ll}
\hline CF-patients & \\
\hline Subjects n & 16 \\
Sex M/F n & $4 / 12$ \\
Age months & $148.0(83-226)$ \\
Height cm & $145.3 \pm 3.9$ \\
Weight kg & $33.7 \pm 2.5$ \\
FVC \% pred & $68 \pm 3$ \\
FEV1 \% pred & $55 \pm 3$ \\
Inhaled steroids n & 6 \\
\hline
\end{tabular}

Data are absolute numbers, median with range in parentheses, or mean \pm SEM. CF: cystic fibrosis; M: male; F: female; FVC: forced vital capacity; FEV1: forced expiratory volume in one second. counter-current circulating ice water. The resulting condensate was collected on ice and frozen immediately at $-20^{\circ} \mathrm{C}$ until analysis. The first collection of exhaled air condensate took place before the beginning of the i.v. antibiotics. Further samples were obtained twice a week at the same time of day during the i.v. antibiotic treatment period.

\section{Hydrogen peroxide measurement}

The concentration of $\mathrm{H}_{2} \mathrm{O}_{2}$ in exhaled air condensate was measured in duplicate with a fluorimetric assay based on the reaction of $\mathrm{H}_{2} \mathrm{O}_{2}$ with horseradish peroxidase to form a compound which oxidizes $p$-hydroxyphenylacetic acid to a fluorescent product, as described in detail previously $[12,20]$. The fluorescent product of the condensate and of a standard solution of $\mathrm{H}_{2} \mathrm{O}_{2}$ were quantified fluorimetrically. This assay showed a satisfactory within subject reproducibility of exhaled $\mathrm{H}_{2} \mathrm{O}_{2}$ values of healthy subjects obtained on two consecutive days and with a 1 week interval [21, 22].

Concentrations of $\mathrm{H}_{2} \mathrm{O}_{2}$ in condensate were obtained by linear interpolation of a standard curve. The lower limit of $\mathrm{H}_{2} \mathrm{O}_{2}$ detection was $0.01 \mu \mathrm{M}$. The equipment was designed to avoid contamination of the condensate with saliva, as saliva is a source of $\mathrm{H}_{2} \mathrm{O}_{2}$. Saliva contamination was excluded, as described previously [21], by measuring amylase in all breath condensates which is a sensitive marker for the detection of contamination of the condensate with saliva $[22,23]$.

\section{Nitric oxide measurement}

In nine subjects NO was measured in exhaled air, following the exhaled air condensate collection. NO was measured with two different sampling methods, each in duplicate. Firstly, off-line measurement via one single deep expiration into an NO-impermeable balloon: subjects were asked to exhale, without breath holding, via a plastic tube, which acts as a flow restrictor and causes elevation of oral pressure sufficient to avoid nasal contamination, into an NO-inert Mylar balloon. This off-line sampling method, including the advantages and disadvantages of this technique, was described earlier in detail [24]. The NO concentration was measured from the balloons. Secondly, in children able to perform more complicated manoeuvres, NO was measured on-line during a controlled slow exhalation from total lung capacity through a mouthpiece and a two way nonrebreathing valve against an in-line resistor (20 $\mathrm{cmH}_{2} \mathrm{O} \cdot \mathrm{L}^{-1} \cdot \mathrm{s}^{-1}$, Rudolph Inc.) with an individually standardized flow rate of $20 \%$ of the subject's vital capacity per second, as described previously in detail [24, 25]. A biofeedback display provided visual guidance for the subject to maintain the exhalation flow at the target level. The mean end-expiratory NO level was measured during an end-expiratory flow plateau of at least $3 \mathrm{~s}$. Between the different expiratory manoeuvres, all children were allowed $2 \mathrm{~min}$ rest, to restore resting conditions of ventilation. To exclude the effect of high ambient NO levels on the exhaled NO values, children breathed NO-free air when the ambient NO was above 5 parts per billion (ppb). During NO measurements, subjects did not wear a noseclip. NO was measured with a chemiluminescence analyser 
(Sievers 280, Boulder, CO, USA) with a sampling flow of $200 \mathrm{~mL} \cdot \mathrm{min}^{-1}$ and a response time of $200 \mathrm{~ms}$. The analyser was regularly calibrated according to the manufacturer's guidelines, employing certified NO gases (100 ppb and 9 parts per million) and certified NO-free gas (HockLoos, Barendrecht, The Netherlands).

\section{Lung function}

All subjects underwent flow-volume measurements immediately after collection of the condensate and measurement of NO. Flow-volume curves were obtained in triplicate (Masterlab Jaeger, Würzberg, Germany). Results of FEV1 and forced vital capacity (FVC) were expressed as percentage predicted [26].

\section{Data analysis}

Results of $\mathrm{H}_{2} \mathrm{O}_{2}$ and $\mathrm{NO}$ measurements are expressed as median and ranges because of a non-normal distribution. Lung function data are presented as mean \pm SEM. Comparison of exhaled $\mathrm{H}_{2} \mathrm{O}_{2}$, $\mathrm{NO}$ and spirometric values before and after antibiotic therapy was performed with the Wilcoxon signed ranks test for paired samples. A two-tailed p-value of $<0.05$ was considered significant. Spearman correlation tests were performed to detect a correlation of changes of FEV1 on the one hand, and changes of NO or $\mathrm{H}_{2} \mathrm{O}_{2}$ on the other hand between the first and last measurements in each child. Correlation between changes of $\mathrm{H}_{2} \mathrm{O}_{2}$ and changes of FEV1 for the individual subjects between all subsequent pairs of measurements was investigated with regression analysis [27].

\section{Results}

During i.v. antibiotic treatment, FEV1 improved from $55 \pm 3 \%$ to $75 \pm 4 \% \quad(p=0.001)$. Figure 1 shows the individual FEV1 data at the start and at the end of i.v. treatment. All subjects completed the condensate collections without difficulty. Of 82 collected condensate samples, three were discarded because of contamination with saliva, as shown by detectable amylase. In two condensate samples, the $\mathrm{H}_{2} \mathrm{O}_{2}$ concentration was below the detection limit. Serial exhaled $\mathrm{H}_{2} \mathrm{O}_{2}$ measurements during i.v. antibiotics showed a decreasing trend with time. The median $\mathrm{H}_{2} \mathrm{O}_{2}$ concentration in exhaled air condensate just before the start of $i$.v. antibiotics was significantly higher than the concentration at the end of the treatment period: $0.28 \mu \mathrm{M}$ (range $0.07-1.20 \mu \mathrm{M}$ ) and $0.16 \mu \mathrm{M}$ (range $0.05-0.24 \mu \mathrm{M})$ respectively $(\mathrm{p}=0.002)$. The individual data are shown in figure 2. During treatment, nine subjects showed decreases in exhaled $\mathrm{H}_{2} \mathrm{O}_{2}$ together with an improvement in lung function, three subjects showed decreases in exhaled peroxide with no consistent improvement in lung function and four subjects exhibited no consistent change in peroxide concentrations with $(n=2)$ or without $(n=2)$ improvement in lung function. Figure 3 shows, for the individual subjects, the negative correlation between changes of $\mathrm{H}_{2} \mathrm{O}_{2}$ and changes of $\mathrm{FEV} 1$ of all different pairs of measurements during the treatment period. The overall correlation, corrected for the number

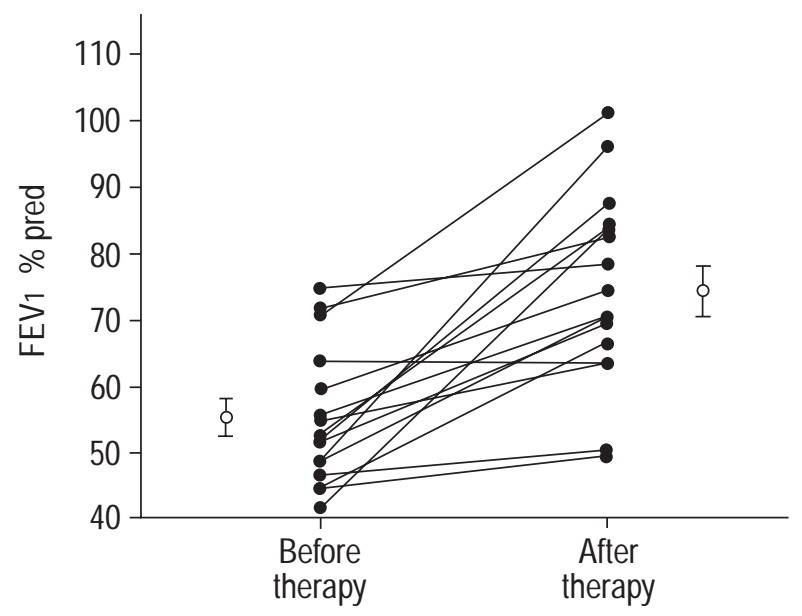

Fig. 1. - Changes in forced expiratory volume in one second (FEV1; expressed as percentage of predicted normal value) before and after i.v. antibiotic treatment of respiratory tract infectious exacerbations in 16 cystic fibrosis patients. 0 : values of individual patients; $\bigcirc$ : mean \pm SEM. The increase is statistically significant $(\mathrm{p}=0.001)$.

of measurements per child, is of borderline significance $(\mathrm{p}=0.08)$. At the onset of each treatment, exhaled $\mathrm{H}_{2} \mathrm{O}_{2}$ levels did not correlate with exhaled NO levels nor with baseline FEV1 or FVC ( $p>0.1$ for each). There was no significant difference in level of exhaled $\mathrm{H}_{2} \mathrm{O}_{2}$ between $\mathrm{CF}$-patients on inhaled steroids $(\mathrm{n}=6)$ and those not on inhaled steroids.

Off-line exhaled NO measurements by means of balloons were obtained without difficulty in all nine children. In contrast, three out of nine children were not able to sustain a stable end-expiratory flow plateau of at least $3 \mathrm{~s}$ for on-line measurements of NO with constant flow. Serial exhaled NO measurements during i.v. antibiotics showed no consistent trend with time. For both sampling methods, the mean NO levels in exhaled air before treatment were not significantly different from those after treatment. Initial values of NO obtained with the balloon method and with slow controlled exhalation were $3.5 \mathrm{ppb}(2.3-6.5 \mathrm{ppb})$ and $4.2 \mathrm{ppb}(3.1-6.1 \mathrm{ppb})$, respectively. At the end of treatment exhaled NO was $3.4 \mathrm{ppb}(2.2-6.8 \mathrm{ppb})(\mathrm{p}=0.6)$ and $4.0 \mathrm{ppb}$

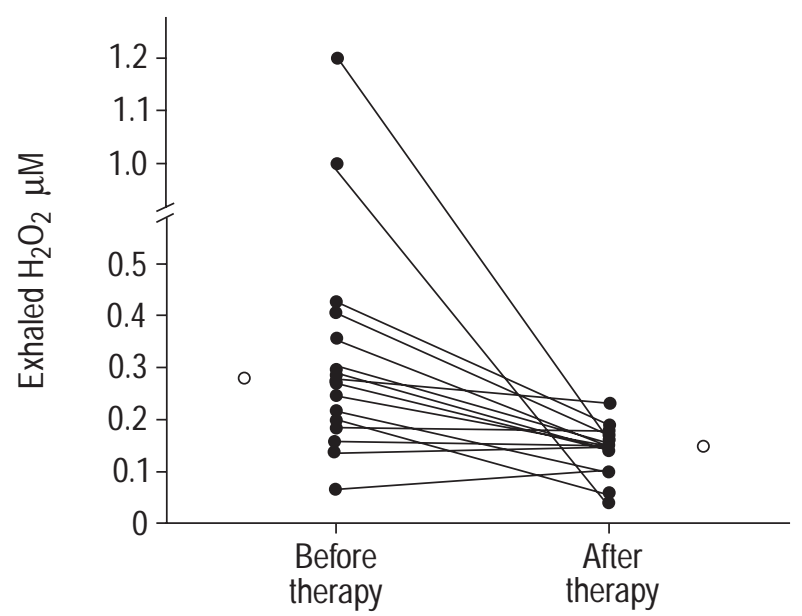

Fig. 2. - Changes in exhaled hydrogen peroxide $\left(\mathrm{H}_{2} \mathrm{O}_{2}\right)$ in 16 cystic fibrosis-patients before and after i.v. antibiotic treatment of respiratory tract infectious exacerbations. $\bigcirc$ : data from individual children; $\bigcirc$ : median values. The change is statistically significant $(\mathrm{p}=0.002)$. 


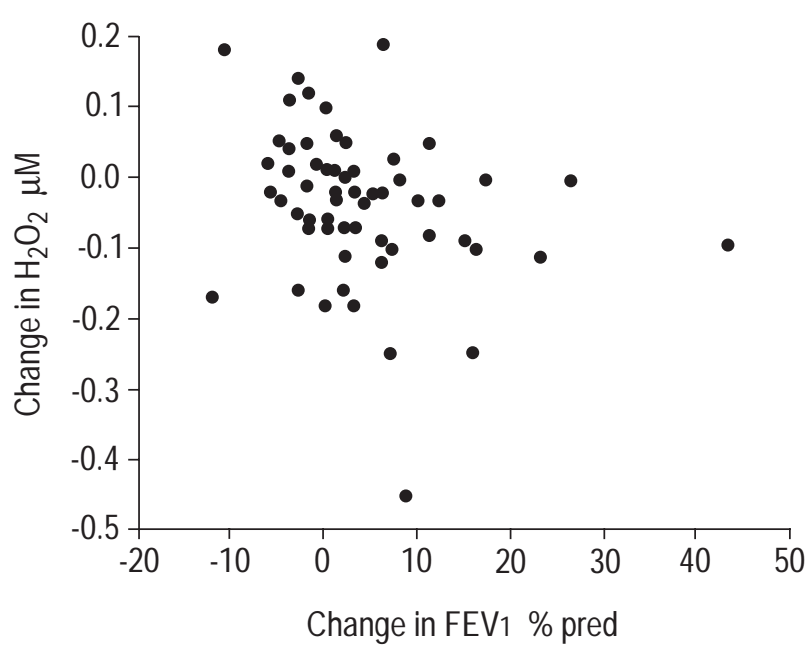

Fig. 3. - Scatterplot of changes in exhaled hydrogen peroxide $\left(\mathrm{H}_{2} \mathrm{O}_{2}\right)$ versus changes in forced expiratory volume in one second (FEV1) in paired observations made during antibiotic treatment of 16 children with cystic fibrosis treated with antibiotics for respiratory exacerbations. Regression analysis, correcting for the numbers of observations per patient, showed a weak correlation of borderline clinical significance $(\mathrm{p}=0.08) . \%$ pred: percentage predicted.

(2.4-5.6 ppb) $(\mathrm{p}=0.4)$ for balloon- and on-line sampling, respectively. The correlation between FEV1 and NO was not significant. No conclusion can be drawn about the effect of inhaled steroids on exhaled NO, because only two of the nine CF-children, in which exhaled NO was measured, used inhaled steroids.

\section{Discussion}

In this study it was found that exhaled $\mathrm{H}_{2} \mathrm{O}_{2}$ was elevated and decreased significantly in CF-children with acute infective pulmonary exacerbations who were treated with i.v. antibiotics. Their lung function (FEV1) improved significantly. Data on exhaled NO were inconclusive and showed no trend.

Careful monitoring of CF lung disease is important, especially in the early stages of the disease where infection and the associated inflammatory response and oxidative stress are frequently insidious and asymptomatic [28]. However, conventional methods to assess airway inflammation are complicated (bronchoscopy, BAL), and sputum may be difficult to obtain in young children. Hence, markers of inflammation like $\mathrm{H}_{2} \mathrm{O}_{2}$ and $\mathrm{NO}$ that can be obtained easily and repeatedly are potentially important for monitoring $\mathrm{CF}$ lung disease. Exhaled $\mathrm{H}_{2} \mathrm{O}_{2}$ levels in adult CF-patients were investigated earlier and appeared not to be significantly different from those of healthy controls $[22,29]$. In this study in CF-children with acute infective pulmonary exacerbations higher levels were found than in healthy children [21], and a significant decrease of serial exhaled $\mathrm{H}_{2} \mathrm{O}_{2}$ levels in the course of treatment with antibiotics was also found. The observed $\mathrm{H}_{2} \mathrm{O}_{2}$ concentrations at the end of the treatment period are similar to those found previously in healthy children [21], and are in agreement with the results of stable CF-adults $[22,29]$. Thus, exhaled $\mathrm{H}_{2} \mathrm{O}_{2}$ may not be a suitable marker of airway inflammation in stable $\mathrm{CF}$ - patients, but is of potential value to monitor the effect of anti-inflammatory treatment for exerbations.

That exhaled $\mathrm{H}_{2} \mathrm{O}_{2}$ is not elevated in stable CF-patients is possibly due to an increase of scavenging by for example glutathione or catalase which may balance the increased oxidative stress [29]. In that case, the results suggest that infective pulmonary exacerbations may disturb such a balance, and this could be due to various mechanisms. For example, increased oxidative stress; bacterial infection could contribute to oxidative stress by recruitment and activation of phagocytic cells in the lung [30], and by inactivating oxygen radical scavenging molecules. McGRATH et al. [8] recently showed that serum inflammatory markers during acute respiratory exacerbations in CF-patient were significantly elevated and showed improvement with antibiotic treatment. Furthermore, alveolar macrophages obtained by BAL fluid from subjects with a recent lower respiratory tract infection released more $\mathrm{H}_{2} \mathrm{O}_{2}$ [31]. On the other hand a decreased antioxidant status; RANGE et al. [32] recently demonstrated in $17 \mathrm{CF}$-subjects with infective exacerbations that treatment with i.v. antibiotics resulted in increased plasma levels of antioxidants.

There was no significant difference in median level of exhaled $\mathrm{H}_{2} \mathrm{O}_{2}$ between CF-patients on inhaled steroids and those not on inhaled steroids. This observation contrasts with results in stable asthmatic children where inhaled corticosteroids were associated with lower exhaled $\mathrm{H}_{2} \mathrm{O}_{2}$ [12]. On the other hand, earlier studies in $\mathrm{CF}$ and bronchiectasis also showed no significant influence of inhaled steroids on exhaled $\mathrm{H}_{2} \mathrm{O}_{2}[13,22]$. A possible explanation is that corticosteroids do not alter the neutrophilic inflammation in $\mathrm{CF}$ as effectively as they affect eosinophilic inflammation in asthma [13]; alternatively, the relatively low levels in CF leave less room for change than the higher levels in untreated asthmatics.

Exhaled NO in CF-children was measured with two different sampling methods: on-line single slow flow controlled exhalation method and off-line via a single exhalation into a balloon. In contrast to the off-line sampling method the on-line NO sampling method recommended by the European Respiratory Society [17] is rather difficult to perform in children. In this study the on-line constant flow method had a failure rate of $33 \%$. In a previous study in a larger study population of 101 stable allergic asthmatic children a similar failure rate of $30 \%$ was found [24]. CANADY et al. [33] showed that $24 \%$ of their studied children $(n=33)$ were unable to perform the on-line measurement at constant flow. Both NO sampling methods were used in this study; exhaled NO levels showed no consistent trend with time in both sampling methods. This result is in agreement with an earlier study by Ho et al. [34] who found no change in exhaled NO levels during 7 days of treatment in eight adults with infectious exacerbation of CF. This suggests that exhaled NO may not be a suitable marker to monitor airway inflammation and to evaluate anti-inflammatory treatment in CF-patients with an infective pulmonary exacerbation. However, for a definitive conclusion on this subject further studies with larger study populations are needed. The initial NO value obtained with the balloon method in the present study was slightly lower than values obtained previously in healthy children with the same sampling method [35]. Other studies also reported exhaled NO levels in CF-subjects that 
were not higher than in control subjects [18, 19, 34]. Whether this finding reflects reduced diffusion and metabolism of NO within the viscous airway secretions or a genuine reduction in airway mucosal NO synthesis is not clear. However, nitrite levels in exhaled air condensate were found to be higher in CF-patients than in normal subjects [36]. This suggests that exhaled NO may not reflect the total NO production in the airways.

The relationship between initial values of exhaled $\mathrm{H}_{2} \mathrm{O}_{2}$ or NO and lung function was not significant. Probably, measurement of lung function and of exhaled NO and $\mathrm{H}_{2} \mathrm{O}_{2}$ give different information about the inflammatory process of the airways. Airway inflammation is only one of the many determinants of airflow limitation. Nevertheless, figure 3 shows a weak negative correlation between changes of $\mathrm{H}_{2} \mathrm{O}_{2}$ and changes of FEV1 between the different serial measurements in individual subjects, and this does suggest that generation of $\mathrm{H}_{2} \mathrm{O}_{2}$ is related to the inflammatory process which impairs lung function in $\mathrm{CF}$.

In conclusion, the study shows that the levels of exhaled hydrogen peroxide are elevated in cystic fibrosis-children with an infective pulmonary exacerbation. Furthermore, in contrast to exhaled nitric oxide, exhaled hydrogen peroxide significantly decreases during serial measurements in cystic fibrosis-patients during intravenous antibiotic treatment. This suggests that exhaled hydrogen peroxide may be a helpful marker to monitor oxidative stress due to airway inflammation in cystic fibrosis-subjects with an acute infective pulmonary exacerbation.

\section{References}

1. Armstrong DS, Grimwood K, Carlin JB, et al. Lower airway inflammation in infants and young children with cystic fibrosis. Am J Respir Crit Care Med 1997; 156: 1197-1204.

2. Davis PB, Drumm M, Konstan MW. State of the art: cystic fibrosis. Am J Respir Crit Care Med 1996; 154: 1229-1256.

3. Bonfield TL, Panuska JR, Konstan MW, et al. Inflammatory cytokines in cystic fibrosis lungs. Am J Respir Crit Care Med 1995; 152: 2111-2118.

4. Dean TP, Dai Y, Shute JK, Church MK, Warner JO. Interleukin-8 concentrations are elevated in bronchoalveolar lavage, sputum and sera of children with cystic fibrosis. Pediatr Res 1993; 34: 159-161.

5. Konstan MW, Hilliard KA, Norvell TM, Berger M. Bronchoalveolar lavage findings in cystic fibrosis patients with stable, clinically mild lung disease suggest ongoing infection and inflammation. Am J Respir Crit Care Med 1994; 150: 448-454.

6. Khan TZ, Wagener JS, Bost T, Martinez J, Accurso FJ, Riches DWH. Early pulmonary inflammation in infants with cystic fibrosis. Am J Respir Crit Care Med 1995; 151: 1075-1082.

7. Winklhofer-Roob BM. Oxygen free radicals and antioxidants in cystic fibrosis: the concept of an oxidantantioxidant imbalance. Acta Paediatr Suppl 1994; 83: 4957.

8. McGrath LT, Mallon P, Dowey L, et al. Oxidative stress during acute respiratory exacerbations in cystic fibrosis. Thorax 1999; 54: 518-523.

9. Kharazmi A, Rechnitzer C, Schiotz PO, Jensen T, Baek L, Hoiby N. Priming of neutrophils for enhanced oxidative burst by sputum from cystic fibrosis patients with Pseudomonas aeruginosa infection. Eur J Clin Invest 1987; 17: 256-261.

10. Hull J, Vervaart P, Grimwood K, Phelan P. Pulmonary oxidative stress response in young children with cystic fibrosis. Thorax 1997; 52: 557-560.

11. Scheideler L, Manke HG, Schwulera U, Inacker O, Hämmerle H. Detection of nonvolatile macromolecules in breath: a possible diagnostic tool? Am Rev Respir Dis 1993; 148: 778-784.

12. Jöbsis Q, Raatgeep HC, Hermans PWM, de Jongste JC. Hydrogen peroxide in exhaled air is increased in stable asthmatic children. Eur Respir J 1997; 10: 519-521.

13. Loukides S, Horvath I, Wodehouse T, Cole PJ, Barnes PJ. Elevated levels of expired breath hydrogen peroxide in bronchiectasis. Am J Respir Crit Care Med 1998; 158: 991-994.

14. Dekhuijzen PNR, Aben KKH, Dekker I, et al. Increased exhalation of hydrogen peroxide in patients with stable and unstable chronic obstructive pulmonary disease. $\mathrm{Am} \mathrm{J}$ Respir Crit Care Med 1996; 154: 813-816.

15. Kietzmann D, Kahl R, Müller M, Burchardi H, Kettler D. Hydrogen peroxide in expired breath condensate of patients with acute respiratory failure and with ARDS. Intensive Care Med 1993; 19: 78-81.

16. Lundberg JON, Weitzberg E, Lundberg JM, Alving K. Nitric oxide in exhaled air. Eur Respir J 1996; 9: 26712680.

17. Kharitonov SA, Alving K, Barnes PJ. Exhaled and nasal nitric oxide measurements: recommendations. Eur Respir $J$ 1997; 10: 1683-1693.

18. Lundberg JON, Nordvall SL, Weitzberg E, Kollberg H, Alving K. Exhaled nitric oxide in paediatric asthma and cystic fibrosis. Arch Dis Childhood 1996; 75: 323-326.

19. Dötsh J, Demirakça S, Terbrack HG, Hüls G, Rascher W, Kühl PG. Airway nitric oxide in asthmatic children and patients with cystic fibrosis. Eur Respir J 1996; 9: 2537 2540.

20. Hyslop PA, Sklar LA. A quantitative fluorimetric assay for the determination of oxidant production by polymorphonuclear leukocytes: its use in the simultaneous fluorimetric assay of cellular activation processes. Anal Biochem 1984; 141: 280-286.

21. Jöbsis Q, Raatgeep HC, Schellekens SL, Hop WCJ, Hermans PWM, de Jongste JC. Hydrogen peroxide in exhaled air of healthy children: reference values. Eur Respir J 1998; 12: 483-485.

22. Ho LP, Faccenda J, Innes JA, Greening AP. Expired hydrogen peroxide in breath condensate of cystic fibrosis patients. Eur Respir J 1999; 13: 103-106.

23. Dauletbaev N, Diegel H, Berkefeld M, et al. Monitoring the salivary contamination of breath condensate by measuring alpha-amylase and urea. Eur Respir J 1999; 14: $166 \mathrm{~s}$.

24. Jöbsis Q, Schellekens SL, Kroesbergen A, Hop WCJ, de Jongste JC. Sampling of exhaled nitric oxide in children: end-expiratory plateau, balloon and tidal breathing methods compared. Eur Respir J 1999; 13: 1406-1410.

25. Kroesbergen A, Jöbsis Q, Bel EHD, Hop WCJ, de Jongste JC. Flow-dependency of exhaled nitric oxide in children with asthma and cystic fibrosis. Eur Respir $J$ 1999; 14: 871-875.

26. Zapletal A, Samanek M, Paul T. Lung Function in Children and Adolescents: Methods, Reference Values. Basle, Karger Verlag, 1987; pp. 191-197.

27. BMDP Statistical Software Manual. Unbalanced repeated measures models with structured covariance matrices. 
Berkeley, CA, USA, University of California Press, 1992: pp. 1330-1335.

28. Wood AJJ. Management of pulmonary disease in patients with cystic fibrosis. $N$ Engl J Med 1996; 335: 179 188.

29. Worlitzsch D, Herbeth G, Ulrich M, Döring G. Catalase, myeloperoxidase and hydrogen peroxide in cystic fibrosis. Eur Respir J 1998; 11: 337-383.

30. Henson PM, Johnston RB. Tissue injury in inflammation. J Clin Invest 1987; 79: 669-674.

31. Greening AP, Lowrie DB. Extracellular release of hydrogen peroxide by human alveolar macrophages: the relationship to cigarette smoking and lower respiratory tract infections. Clin Sci 1983; 65: 661-664.

32. Range SP, Dunster C, Knox AJ, Kelly FJ. Treatment of pulmonary exacerbations of cystic fibrosis leads to improved antioxidant status. Eur Respir J 1999; 13: 560-564.
33. Canady RG, Platt-Mills T, Murphy A, Johannesen R, Gaston B. Vital capacity reservoir and online measurement of childhood nitrosopnea are linearly related: clinical implications. Am J Respir Crit Care Med 1999; 159: 311-314.

34. Ho LP, Innes JA, Greening AP. Exhaled nitric oxide is not elevated in the inflammatory airways diseases of cystic fibrosis and bronchiectasis. Eur Respir J 1998; 12: 1290 1294.

35. Jöbsis Q, Kroesbergen A, Schellekens SL, de Jongste JC. Nitric oxide in exhaled air of healthy children, sampled with the balloon method. Am J Respir Crit Care Med 1998; 157: A469.

36. Ho LP, Innes JA, Greening AP. Nitrite levels in breath condensate of patients with cystic fibrosis is elevated in contrast to exhaled nitric oxide. Thorax 1998; 53: 680684. 